\title{
The mediatization of deviant subcultures: an analysis of the media-related practices of graffiti writers and skaters
}

\section{Kameliya Encheva, Olivier Driessens and Hans Verstraeten}

MedieKultur 2013, 54, 8-25

Published by SMID | Society of Media researchers In Denmark | www.smid.dk The online version of this text can be found open access at www.mediekultur.dk

This article studies the mediatization of criminal and deviant subcultures by analyzing the media-related practices of graffiti writers and skaters in Ghent, Belgium. The ethnographic analysis shows how these subcultures orient themselves toward media and how media become an essential part of and change their everyday practices. Three consequences of this mediatization are highlighted: First, by emphasizing their artistic and performative skills through the mediation of their practices, these subcultures start losing their rebellious and oppositional image. Second, as such, it can be observed that they increasingly become part of mainstream culture. Third, our analysis demonstrates how the mediatization of subcultural groups and their practices goes hand in hand with their commercialization and commodification, as they engage in recording and disseminating their work not only for artistic reasons but also as a means of acquiring sponsorship deals and job opportunities.

\section{Introduction}

The ongoing expansion of media and communication technologies and the deep embedding of mediated communication in society and culture have resulted in what is generally called 'media-saturated societies'. Media have contributed to temporal-spatial distancing and are increasingly changing the foundations for human action and communication. 
The concept of mediatization has been introduced to describe these social and cultural changes related to the intensification of media. An interdisciplinary and fast growing research field has now been established around this concept, yet as is the case with most new fields, mediatization studies have prompted semantic and conceptual debates. We can refer here to discussions concerning the parallel use of different labels such as medialization and mediation alongside mediatization (see Livingstone, 2009), which is indicative of mingling and merging of different traditions and approaches: the Anglophone tradition with its preference for mediation on the one hand and the Germanic and European use of mediatization on the other. Yet mediatization seems to be overcoming mediation as the concept that captures the co-articulation of changes in both media communication and society and culture (see Hepp, 2012). For instance, whereas Couldry preferred mediation instead of mediatization in his earlier work (see Couldry, 2008), he recently switched sides and now endorses mediatization (see Couldry, 2012). Simply put, in contrast to mediatization, mediation is understood as communication through media.

As a result, because of the ongoing conceptual and theoretical debates, relatively little energy has been invested in empirically grounded studies (see Hepp, Hjarvard \& Lundby, 2010). A further limitation is that, within this small pool of empirical studies, focus has rested primarily on politics (e.g., Campus, 2010; Kepplinger, 2002), thus largely neglecting other social fields that are equally worth studying. Exceptions are analyses of the mediatization of religion (Hjarvard, 2008a; Hoover, 2009), consumption (Jansson, 2002), and fashion online (Skjulstad, 2009). This article aims to address the gap in mediatization studies on crime and deviance. One example that immediately comes to mind is obviously the carefully prepared, filmed, and meticulously executed school shooting (e.g. Kolenic, 2009). Interestingly, the Columbine and Virginia Tech school shootings have raised the question as to how "seemingly secretive" illicit worlds (Ferrell, Milanovic \& Lyng, 2001) can be reconciled with a broader visibility that accompanies its mediatization. School shooters such as Eric Harris, Dylan Klebold, and Seung-Hui Cho have successfully incorporated the YouTube motto of 'Broadcast Yourself' by staging illicit acts for broadcasting. They videotaped manifestos and sent photos of their criminal act to the news media. These criminal and deviant acts have thus come to resemble carefully staged and produced fiction programs rather than acts of anarchy or resistance. This intensified relationship between crime, media, and criminal cultures challenges our understanding of deviant (sub)cultures. Furthermore, following Greer (2009), we will argue that mediatization as a concept is relevant and necessary for understanding contemporary criminal cultures and deviance.

This article focuses on one specific type of crime and deviance, namely crimes of style. Common examples are public performances by BASE jumpers (who jump from buildings or bridges) (Ferrell et al., 2001), graffiti writers, skaters, and BMX riders, all of whom perform most often in urban settings. Underground criminal or deviant subcultures are typically defined by expressivity and lifestyle. As a result, media - as a dominant distributor of signs and symbols - can be of essential importance to these groups. Reconciling their rebellious 
identity, image, and lifestyle with the new communicative environment is of great importance (see Thornton, 1995). Here, we focus on the various media-related practices of the criminal and deviant subcultures of graffiti writers and skaters. For example, Pietrosanti's question of "Does it really matter anymore to see the train running with the piece on it as long as the picture is on the web?" (2010, p. 77) signals the radical shifts that the mediatization of graffiti writing involves, not only for the visibility of the work or for its changed consumption but also for the writers' practices and how they deal with media while creating and performing. Indeed, this highlights the tension between giving their (sometimes) illegal activities more exposure and avoiding getting caught while performing their risky practices.

Drawing on observations of and in-depth interviews with graffiti writers and skaters, we describe the mutual shaping and transforming of rebellious subcultures by the embedding of media in their illegal and deviant practices. First, we will demonstrate that increased mediatization shifts focus away from the oppositional and rebellious nature of these underground subcultures to an image of groups that most value skills, performance, and even spectacle. Second, the symbols and signs of these subcultures, "bricollaged into lifestyles" (Hayward \& Young, 2004, p. 260), have inevitably taken part in dynamic mediation and remediation, which has created the paradox of the underground movement. Instead of being intolerable and in conflict with society, the underground becomes part of the cultural mainstream (Duda, 2010). Third, consolidating post-subcultural discussions (see Muggleton \& Weinzierl, 2003), the following cases will show that mediatization goes hand in hand with an increasing commercialization of these subcultures even though they often claim to being opposed to corporate values. Our research shows that this process goes beyond subcultural styles freezing in commodification (Hebdige, 1979).

\section{Mediatization}

The term mediatization describes the co-articulation of social and cultural changes on the one hand and changes in media and communication on the other (see Hepp, 2012). In our media-saturated societies, the proliferation of technology leads to a situation in which most people and organizations use e-mail, radio, TV, the internet, chat, and mobile phones daily without even realizing the high intensity of their technologically driven existence. Mobile phones, the internet, and social networks offer different ways of structuring our thoughts, ideas, and social practices. They thus directly and indirectly influence the "grammar of media communication" (Lundby, 2009a, p. 8) and hence influence our behavior and practices. When these rules and strategies are adopted and translated into one's behavior, media influence actors not just through their content but also through the existence of the technology itself (Schrott, 2009).

This also implies that thinking in terms of causal logics would only marginalize the discussion in a situation in which the media have become environmental (Silverstone, 2007). Mediatization allows us to look beyond the causal logics. In this sense, we see media not only 
as a mere transmitter of messages and information but also as an influential environment that shapes different social and cultural spheres through its grammar and characteristics. The "new and changing media potentials" (Thomas, 2009, p. 270) give rise to new behavioral patterns, stylized according to the "omnipresent symbolic environment" of the media (Schulz, 2004, p. 93). From this perspective, mediatization points to how social activities and practices are shaped and reshaped in the presence of and through interaction with media.

According to some authors (e.g., Hjarvard, 2004, 2008b; Krotz, 2001; Schulz, 2004), this (re)shaping is manifested by what they call 'media logic'. However, this concept has been criticized for being linear (Couldry, 2008; Hepp, 2009) and singular (Lundby, 2009b). Therefore, in order to grasp the dynamics of the mediatization of crime and deviance, it can be fruitful to explore alternative analytical frameworks, for example practice theory (see Couldry, 2004; Reckwitz, 2002; Schatzki, 1996), as suggested by Couldry (2012) and Driessens et al. (2010). The main advantage to this paradigm is that it offers deeper insight into the "open-ended range of practices focused directly or indirectly on media" (Couldry, 2004, p. 117) and avoids the mediacentric approach that can be found in many media studies. Practice theory makes it possible to move beyond the causal relations of the media effects studies and to examine the media-crime relationship in terms of practices oriented towards the media.

\section{Criminal subcultures and media}

Criminal and deviant behavior is certainly not a solely modern phenomenon. Neither is the popular belief that media and (especially violent) crime have a somewhat natural connection (Jewkes, 2004). Although literature reviews typically conclude that there is no such evidence, scholarly debate on media and crime has often associated viewing violent media with aggression (e.g. Anderson, 2002) or has highlighted the power of (mass) media campaigns and images for labeling certain behavior as deviant (Hamm \& Ferrell, 1994). This labeling perspective has served as a theoretical backbone for cultural criminology - a tradition placing crime and its control in the context of culture, symbolism, and imagery (Hayward \& Young, 2004). It is here that the general inquiry into media, culture, and crime merge into one domain of interest, highlighting the existence of the so-called 'crimes of style" or, as Ferrell puts it, subcultural criminal behavior "collectively organized around networks of symbol, ritual, and shared meaning" (Ferrel 1999, p. 403; see also Ferrell \& Sanders, 1995; Kidd-Hewitt \& Osborne, 1995).

The extant literature on subcultures regards criminal and deviant subcultures as rebellious, oppositional, and resistant to mainstream culture and social norms (see Hebdige, 1979; Hall \& Jefferson, 1993). This is, in turn, the attitude concerning mass media, as the criminal and deviant subcultures are being regarded relative to mainstream values and dominant culture. Yet with the increasing use of social media, mobile media, and the like, mass media represent only a tiny piece of the puzzle called media-saturated societies today (Lundby, 
2009a). The traditional research agenda is pervaded by questions of what media do with or say about criminal subcultures. The "intensification" of media (Hartmann, 2009, p. 226) and their proliferation across almost all aspects of social and cultural life make it interesting to shift focus in the opposite direction and explore what the members of deviant and criminal subcultures do with media or how they embed them in their "seemingly secretive" illicit worlds (Ferrell, Milanovic \& Lyng, 2001). This is at the heart of our empirical study.

\section{Method}

The present study looks at criminal and deviant subcultures through the prism of mediatization. We choose to examine two prominent subcultures, namely those of graffiti writers and skaters, by looking at how they embed media in their practices. Nevertheless, the aim of this research is not to compare or look for differences between these two subcultures but, rather, to examine where the commonalities lie with regard to their media-oriented practices. This is also where the strength of the concept of mediatization lies. We could probably trace similar trends across relatively related fields. Moreover, as our research shows, besides the illicit aspects of their practices, both graffiti and skateboarding subcultures appear to have even more in common. For example, a lot of graffiti is done in and around skate parks and popular skate spots.

Our ethnographic approach consists of ten in-depth interviews in addition to a modest amount of participant observation (March-April 2011). In order to better understand these subcultures, we also interviewed a member of the Graffiti Youth Organization, which supports young graffiti writers and organizes workshops on legal graffiti in Ghent, Belgium. The respondents, who were selected after theoretical sampling, are four graffiti writers and six skaters (of which three are sponsored). Their age ranges from 15-33, and they are all active in the city of Ghent. One respondent is American, and the others are all Belgian. All respondents are male, which follows naturally from the fact that many of these subcultural groups are particularly masculine and often contain very few female members. In light of this article's research question on the media-related practices of subcultural members and their possible consequences, a criterion in selecting the respondents was their relative involvement with media (technologies). Hence, even though some have a history of illegal practices, it could be said that most of them are now closer to mainstream culture than to criminal culture in the sense described above.

The semi-structured interviews were conducted using a topic list with the following themes: general information about their subcultural activity, media-oriented practices, their feelings towards and view on their subculture, and several questions about illegal activities and confrontations with law-enforcement organizations. The respondents were guaranteed anonymity and the confidential use of data. Therefore, when quoting or referring to respondents, we use codes such as SUS9 or GBE1. The first letter refers to skating (S) or graffiti (G), the next two to the nationality (Belgian (BE) or American (US)), which 
is followed by a numerical index. The collected data were thematically coded using NVivo into six main categories, ${ }^{1}$ which have been deducted from the literature. Some concepts emerged after interpretation of the transcripts and were added as free nodes.

\section{Results}

The results of our research reveal that understanding criminal and deviant subcultures is impossible without acknowledging the importance of the diffusion via media (or mediation) of their practices which renders them public and accessible for wider audiences. Through mediation, the underground has become visible to society. This pervasiveness of media practices in illicit worlds, Ferrell et al. (2001) argue, signals an emerging reconceptualization of deviant and criminal subcultures - as well as their mediatization. Reaching a wider audience has, to a large extent, shifted the emphasis from deviance and resistance as central values to artistic skills, aesthetic production, and performance (in the case of skating and graffiti writing). Instead of performing symbolic forms of resistance or addressing society with a political message, deviant and criminal subcultures have, in contradiction to themselves, embraced the new media potentials specifically to mediate their skills, share knowledge, promote themselves, and convince the world that they are artists, not criminals. Or in the words of our respondent GBE1, "They are the next best thing."

Still, and this is a crucial point, even though the subcultures under study in this article are incorporated into mainstream society and have to a certain extent become regarded as leisure activities, it is important to acknowledge that they remain deviant to some measure. More specifically, the subcultural activities of skating and graffiti writing are often moved to legitimate localities such as skate parks or special murals or streets where they are allowed. This implies that skating or painting in non-sanctioned areas is often met with sanctions or fines or, in the case of skateboarding, that the city's architecture is changed so as to impede skaters from performing in certain spaces. An example is changing handrails or staircases in such a way that skaters can no longer do their tricks on them (see also Orpana, 2011).

\section{"The next best thing" or the importance of art, performance, and spectacle}

The respondents want to show the world that they are the next best thing by posting drawings, photos, and videos of their work on the internet (through blogs or social media), TV shows, and their own (niche) magazines. The increasing mediation of these subcultures (and the broader shift towards creative economies and immaterial production) has taken them from the underground to the surface of mainstream culture, where the "subcultural misfits" (Nelson, 2010, p. 1162) have turned into artists and performers, which can be seen as an example of mediatization. Graffiti artists and skaters embed media in order to eternalize their pieces, tags, throw-ups, ${ }^{2}$ or - in the case of skaters - tricks, what Willard has called "tricknowledgy" (1998, p. 333). Respondent GBE2 explains why it is essential for graffiti writers to take pictures of their work: 
Graffiti is a one-day art. You do something, you take a picture of it. If you do it illegally, it could be gone the next day because the people will clean it up. And if you do it in a legal place, they will go over it.

Often it goes further than taking a picture. Fame, respect, and recognition, "the point and purpose of graffiti" (Macdonald, 2001, p. 74), should be earned not only through throwups, pieces, and tags but also online, showing the whole world "how good they are" (GBE1), resulting in a constant mediation of one's work.

Parallel to the "elongation of meaning" (Ferrell et al., 2001) and quest for fame, they have also made their ephemeral illicit acts visible from their point of view. In other words, deviant subcultures manage to change the perspective: They expand perceptions beyond 'crime' and reframe our thinking of deviance in such a way as to cause more people to begin appreciating graffiti and skating as something valuable, as something other than a property offence or destruction. This goes further than the process of self-defense via one's own niche and micro media, as suggested by McRobbie and Thornton (1995). The intense integration of media practices turns subcultures into active producers rather than vulnerable groups ambiguously defending themselves. From this perspective, our data show that not only do graffiti artists and skaters consider themselves non-deviant, but they also hold that more people have begun to appreciate them for being creative and talented as a consequence of the increased circulation of self-produced images. Through their publicly mediated practices, illicit 'backstage' activities become documents of artistic skills and aesthetic production (Ferrell, 1996). The members of the Graffiti Youth Organization in Ghent explain that, with growing media visibility, people have opened their minds to graffiti as art, inviting writers to create "a masterpiece" in the bedroom of a 13-year old or creating a mural in front of which wedding pictures should be taken.

Similarly, skaters count on HD cameras and fish-eye lenses to show "how difficult it is, and how many details there are, and how technical you need to be" (SBE10). Embedding professional video equipment and special filming techniques - such as close-up shots and special lower shooting angels - places the tricks, skills, and performance in the limelight. The fact that "when you grind some of the ledges it kind of destroys them" (SBE6) is of minor importance in this case. One of the most common (preferred) ways of photographing a trick with a still camera is to make a sequence of shots. Such a sequence consists of multiple pictures taken to capture and showcase a single trick, again emphasizing performance skills (see also Snyder, 2012).

Several criteria were highlighted by respondents as to when a trick should be filmed: It should be difficult, original, and landed properly. One of the respondents (SBE10) complained that it could sometimes take more than two hours to land a difficult trick in front of the camera, but they would still keep trying and keep filming because it is important to have it recorded. Moreover, filming and skating have become so intertwined that this potentially illicit practice has become "indistinguishable from the mediated representation of it" (Ferrell et al., 2001, p. 178). 
This has in turn fueled a further increase in the mediatization of skating. As a result, when asked, most respondents could even point out a structure in skating films or, as SUS9 explains with annoyance, "It begins and you see skating. You would probably see some falling, maybe a clever joke. It depends. At the end will be the great trick that no one thought you could do." Again, the emphasis on the trick, its level of complexity, the skater's skills (and also the location) are central to media presentations and representations of skating.

Moreover, not only is the focus on the technical performance, but mediatization manifests itself through an evolution in the skill level of skating. Respondents explain that the skill level of skating "keeps growing" (SBE7) and nowadays, because of the ever-increasing mediation and remediation, it has reached the "absurd" (SUS9), the unthinkable level:

Because people see it and they naturally mimic it. What you see in the videos, and what you see in the magazines, is what kids will try next. But then they push it up, so it constantly raises the bar. (SUS9)

Similarly, what graffiti writers see online will be the next thing they will do: They learn new drawing techniques and adapt their own styles because "You're into street art and you know that this guy is really good. So you're going to adopt a lot of these things in your own work" (GBE1).

The ability to capture something on your mobile phone and instantly upload it to the internet or to produce semi-professional video material for a reasonable price are just a couple of examples of how the variety of potentials inherent in today's media and communications technologies allows subcultures to manage their image through media products and content. This is to a greater degree what Driessens et al. (2010, p. 321) refer to as "retaining control over media" or deviant subcultures now having a greater ability to decide to what extent they wish to be visible and how they are going to appear in the public space. In this regard, media-oriented practices are also image-producing practices for illicit subcultures (Dayan \& Katz, 1992). Contrary to traditional label theory, deviant and criminal subcultures can now hardly be regarded as passive victims of mass media but instead consist of media-savvy individuals that embed media for the purpose of communicating their artwork and identity.

Despite the underground and subversive nature of graffiti, a lot of artists have substituted the anonymity of their tags with a public profile on MySpace, Facebook and Flickr. Graffiti writer GBE3 explains: "I have over 1500 people on Facebook that can see my work. I think it's a really good medium for artists or everybody who's doing something to show to the world." This dynamic reveals, according to Ferrell et al. (2001), that deviant subcultures are less passive objects of mass media and more active producers of their own image. The artistic and performative nature of the deviant subcultures are reinforced by the fact that the subcultural practices are not opposed to everyday life and mainstream culture as previously claimed by subcultural theorists but, rather, integrated into it. Most respondents have turned graffiti writing into a profession or have combined it with studying graphic 
design at school. The interviewees referred to graffiti as an art process in which creativity, color, drawing techniques, and refinement of one's work were of greater importance than the ability to undermine authority or "reclaim public spaces" (Ferrell, 1996, p. 35). The illegal world of graffiti is also part of the wider route to an artistic career and exhibitions. In this respect, one of the respondents explains that keeping a photo log of your legal or illegal works is essential because it serves as a portfolio (GBE2). Accordingly, skaters make 'sponsor me'-type films to show their best tricks. We will return to this later.

Of course, it would be an exaggeration to reduce this reconceptualization of criminal and deviant subcultures to an isolated manifestation of mediatization. Although there is no question of regarding understanding and acceptance of deviant and criminal subcultures without reference to media, other aspects of modern society must be taken into consideration as well. Mediatization should be viewed as on a par with urbanization, individualization, commercialization, and other -ization meta-processes, all of which contribute to the 'disembedding' of social relations from existing contexts - for instance, those of crime and deviance - and to their being 're-embedded' in new social contexts, for instance those of art and performance (Hjarvard, 2008b).

\section{Style: in-group cohesiveness and mass incorporation}

In this section, we will consider the manifestations of mediatization with regard to the "flamboyant" style of criminal and deviant subcultures (Hebdige, 1979). Theorists inspired by cultural studies generally consider subcultural style to enhance both in-group cohesiveness and dissociation from dominant culture. With the omnipresence of media, which have also increasingly become resources for lifestyle development across society, it is important to revisit this view (Atkinson \& Young, 2008). Several scholars (e.g., Donnelly, 2008; Reinhart, 2008) support the primary argument being made, namely that, through mediation and remediation, style and subcultural symbols are no longer authentic and subculturally significant. Instead, they become more and more part of mainstream culture. In other words, the "incorporation myth" (Marchart, 2003, p. 85) is probably not a myth. If most youngsters are wearing baggy trousers, they can hardly be regarded as a sign of being alternative and oppositional to mainstream culture. The greater visibility and recognisability of these subcultural styles and symbols have in a way recoded the meaning they had for deviant subcultures. In this respect, if the flamboyant style is no longer a sign of resistance but is mass incorporated into mainstream culture, then the second function of subcultural style enhancing in-group cohesiveness can be questioned.

Several of the older respondents in our research could easily draw a line between 'now' and 'back in the day'. Now is the time when little attention is being paid to what you wear, what kind of music you prefer, or whether you speak the same way as the other members of the group. Back in the day refers to exactly the opposite - when style was an important part of the subculture. One of the respondents turns with nostalgia to the time when he started skateboarding: 
First, I bought some roller blades and I went to a skate park. I saw a lot of guys skateboarding and wearing baggy pants and a fool cap. It looked very cool. Also [because of] the game "Tony Hawk's skateboarding", I thought: I need to have a skateboard. I bought one and I never stopped. (SBE7)

These were also the times when skating and graffiti began their expansion via mass media channels, video games (such as the Tony Hawk series), and various (niche) magazines (Skateboard Mag, Transworld Skateboarding, etc.), but this was also the time at which some of the cult films emerged that prompted youngsters to engage in deviant subcultural practices. GBE2 indicates that, with the rise of MTV programs dedicated to rap, hip hop, and graffiti as well as cult films like Wild Style, graffiti became more visible and attractive. The same trend is visible with skateboarding and its incorporation in competitions, commercials, and TV shows. SBE8 explains that seeing skating in commercials actually stops people from "hating it" and causes them to appreciate it to a certain degree. Donnelly (2008) argues that ESPN and the X-Games have shifted the alternative subculture to the mainstream by mediating it. The flamboyant style is becoming fashionable even in the mainstream, thereby blurring the boundaries of what is outlaw and oppositional on the one hand and what is mainstream and fashionable on the other. In the same vein, Atkinson and Young (2008) argue that clothing, language, and music subcultures become fashionable in the larger culture through the widespread distribution of style, minimizing their resistant or subculturally oriented natures and leading as a result to the "seemingly inevitable mass incorporation" of underground, deviant subcultures. In this respect, it is unsurprising that our respondents neglect the importance of subcultural style or label clothes:

In the '70s and '80s, people were always wearing baggy jeans and baggy shirts, and skateboards were very wide with tiny wheels. And nowadays people [skaters] are more fashionable and are wearing regular or tight pants and medium shirts and punk looks. In the '70s and '80s you didn't have that- it was all messed up hair and stuff like that. (SBE8)

Now, the common subcultural clothing style of deviant and criminal groups appears to be the "fast-fashion clothing style of H\&M", as three of our respondents explain: "You can also go skating with clothes from H\&M" (SBE7), "Everybody wants to go to shop at H\&M" (GBE2), and "I always wear Nike's [shoes] because they feel right to skate with, for shoes. But my trousers are H\&M. And they feel right" (SBE8).

Because of the media appropriation of these subcultural styles (Rinehart, 2008), the sense of outlaw and being outsiders to the mainstream casts doubt on Hebdige's (1979) claim that subcultural styles enhance in-group cohesiveness. When the style of deviant subcultures has been adopted at all layers of society and culture, it is difficult to claim that these deviant groups signify belonging through the way they dress, speak, or behave. In our brief observations of graffiti writers and skaters, we failed to notice any differences in style that could identify the group to which the respondents belong. It is interesting to note though that the skaters expressed their irritation over the fact that even people who have 
never been on a skateboard wear skate shoes. Slip-resistant shoes are essential for good performance and are more than style accessories. These subcultures have felt robbed of their most important signs of belonging and have had to reach out for new ways of sustaining in-group cohesiveness.

Interestingly, one of the ways of creating and affirming their sense of community appears to be through the production and distribution of media texts and products. The interviews with skateboarders involve frequent mention of the skate videos they produce with friends. As noted above, there is a common structure in these videos, consisting of both montages of individuals (with the skilled ones performing the best tricks) and groups of skateboarders. By both highlighting the individual styles of each skateboarder and blending them together in group montages, Yochim (2007) argues, the videos suggest that skateboarding is a culture that values individuality yet also promises "the benefits of cooperation and inclusion in a larger group." Several of our respondents attest that friends are an essential part of skate movies:

For making a regular movie, you start with an intro, some intro shots. And then you have the first part, that has to be the part that amazes people, you have the very good skater. And then you have the friends part, and then the last part has to be the best. (SBE8)

By shooting the movies together, skaters make up for the lost sense of belonging. Sometimes, this sense of belonging is also transferred to a crew or to a specific location. One of the respondents explained that they were filming friends and skating "in the streets in Tampa" (SUS9) while another pointed out the main reason for shooting a movie is to represent the scene in Ghent (SBE5). In common with the skaters, a graffiti writer (GBE3) also attests to making movies with his crew.

In the same vein, Furness (2005) has pointed out the importance of deviant subculture labels, (fan)zines, and distribution network. By creating alternative media texts or other media products, they create a field for the like-minded so as to enhance the sense of community that has been partially lost due to the mass incorporation of their subcultural signs of belonging. According to Scott Spitz, author of the bike zine Leapfrog, "Bike zines can certainly reflect what certain communities are doing, but they've also been known to create communities" (quoted in Furness, 2005, p. 122). Our respondents have not shown any specific affection towards magazines or fanzines.

Magazines are cool, and TV channels are also cool, but I don't use a lot of magazines anymore because I can see everything on the internet. It's still charming to have a magazine to look in. It's fun. But if I hear stories of the older graffiti writers - they knew that in Amsterdam there was somebody that published a magazine - a long time ago, the first graffiti magazine or something, and they had a trip from here to Amsterdam to just get the magazine. That won't happen in my life, you know. If the internet crashes maybe, but not now. (GBE3) 
On the one hand, the internet seems to have partially taken over from 'charming' magazines the function of creating a sense of community. On the other hand, the web sites of these magazines - often extensions of the more traditional printed versions - are still sources of information and inspiration for these subcultures. But the potential of internet goes beyond this because it facilitates simple, cheap, and worldwide distribution (Yochim, 2007); it has a short publication lag-time (Nelson, 2010); and provides for interactivity and intertextuality.

Deviant subcultures implement not only popular video sharing sites, such as YouTube and Vimeo, but also specialized discussion platforms (e.g., deviantart.com). There is, for example, also a very useful tool for skaters, Trickipedia ${ }^{3}$, which offers a kind of how-to section for skateboarding tricks. Nor should social network sites (SNS) be disregarded, as they have emerged precisely as an attempt to build communities. All respondents were active on various SNS. As one of them noted, "I think, if you don't have Facebook you don't exist" (GBE3).

\section{Commercialization}

So far, this article has looked into how the mediatization of deviant subcultures has been a powerful impetus for their mass incorporation in society and culture, thereby providing these subcultures with a new set of aesthetic ideals (Hughes, 2009). In this section, we focus on another consequence of their mediatization, namely their commercialization. The commercialization of subcultures has had negative connotations, mostly for members. Nevertheless, most members acknowledge that the spin on commercialization has also had its benefits: More money means more skate parks (SBE10) or more free clothing and shoes (SBE8). Major brands - such as ESPN, Nike, VANS, Quicksilver, Red Bull, and Coca Cola have turned into endorsers of alternative subcultures and synonymous with sponsorships. The mass incorporation of deviant subcultures has only been intensified by the ongoing mediatization and commercialization. Combined, both processes have changed the face of deviant subcultures. Through advertisements and product placement or what Hughes (2009) argues to be mass media outlets of alternative underground cultures, these groups begin appealing to young consumers worldwide, further accelerating the process of their inclusion into the mainstream. Our respondent SBE8 offers the same explanation for the reconceptualization of deviant subcultures: "Now, these days, it's getting more appreciated. You see it in commercials and [...] people [...] are not hating the skating; they actually appreciate what people are doing with their lives, as long as they are happy."

It thus seems that being open to corporate interest is no longer a taboo. The apparently "unwanted nuisance of graffiti" (Hughes, 2009) has evolved into a powerful advertising tool for attracting youth attention. Being recruited to create advertising campaigns for corporations is not uncommon: 
I have a project for VANS OFF THE WALL - the skate brand of the footwear - and I have to do the whole Benelux warehouse. I have to do an exposition there, so I hope I can proceed with the graffiti. (GBE3)

Not only do media contribute to bringing these deviant subcultures to the surface, their members also actively embed them to promote themselves. Even though the origins of graffiti and skating are in the lower-class suburbs, the remnants of resistance to social inequality or corporate bureaucracy are scarce today. In contrast to the image of rebellious subcultures from "deprived environments" (Dickens, 2008, p. 476), contemporary skaters and graffiti writers are more consciously putting effort into organizing and promoting themselves in the more formal art and commercial spheres. Indeed, members of subcultures increasingly embed various media (digital, mass, niche, etc.) in order to take more control of the profitability of their work and performance. Illegal tagging, pieces, and throw-ups are seen as part of a career: "De la rue à la scène" (GBE2), i.e. "From the street to the stage." One starts by exercising in the street, but the ultimate goal is to build a (professional) career:

A few years ago, I painted two times a week. [...] That was a little bit different because I have bills to pay now. I'm working more for people than for myself. Because of the time I had, I put a lot of money in just painting for fun. I could exercise and get better in what I'm doing. (GBE3)

One of the graffiti artists explains that embedding media is "part of the strategies that you have to use to get jobs" (GBE1) (painting murals, advertising, graphic design, etc.). Creating a "portfolio" (GBE2) of your work (for instance, by sharing photos on Facebook, Flickr, or specialized sites such as deviantart.com) is the way to promote oneself and reach major corporations. Similarly, skaters point to the significance of 'sponsor me' tapes consisting of their best tricks:

It's also important because if you skate a lot, shoes and stuff are expensive. If you reach a certain level with skateboarding, you can have a sponsor. But no shop is going to sponsor you if they can't see what you can do with a skateboard. So then you have these movies. (SBE7)

Producing such 'sponsor me' tapes is thus not uncommon. Although it is not the only way to be discovered, as one of our sponsored respondents argues, it is certainly the most traditional and preferred method. This trend has increased not only the importance of skateboarding skills, tricks, or technique itself but also its visual representation. In other words, skating and filming are now caught in an endless spiral of mediation, changing the subcultures' practices and representing its mediatization. Creating videos, photos, or other media products in the hope of gaining success, recognition, symbolic capital, visibility, sponsorship, etc. is an additional stimulus for the further mediatization of these subcultures. Skateboarders have come to consider with great care the formal norms of professional videos, carefully choose appropriate music, and use high definition digital cameras and editing software: 
There's a little evolution in skateboarding films actually. Back in the day, the quality was not good. But that was also not the intention. You want a series of cool tricks with cool music. Now, they also want [to improve] the image, [devote] a lot of attention to montage, cutting and editing, and perfectly [synchronize] the music with the tricks. Actually, it became more professional today. (SBE7)

Nevertheless, the attitude toward commercialization is becoming more positive. Three of the skaters we interviewed were sponsored either by a big corporation or the local skate shop. For these skaters, the videos and photos take on a different dimension. They no longer represent a means of promoting the self but, rather, of promoting the company for which one skates, thereby commodifying the self and the subcultural practices. In order to keep the sponsors satisfied and interested, our respondents attest, you need to film your tricks: "When I land tricks, and I have it on video, or when I have pictures in magazines, it's good for the sponsors. Then they're happy" (SBE10). Even making amateur skate movies is good, "brings money" (SBE7) to the sponsors. It thus seems that the previously considered resistant and oppositional deviant subcultures - the ones believed to engage in criminal self-expression (Manco, 2002) - are now actively collaborating with the industry and the corporate world. As such, this provides an instance in which commercialization goes hand in hand with mediatization.

\section{Conclusion}

The central premise of this article is that media-saturated societies have challenged the capacity of apparently secretive criminal and deviant subcultures to maintain these conditions. By embedding media in their then underground practices, skaters and graffiti writers have come to the surface of society and mainstream culture. The pervasiveness of media-related practices in these partly illicit worlds has broadened the possibilities for selfexpression beyond acts of resistance and rebellion. In addition, deviant subcultures were handed a tool for legitimating their activities and influencing the general public's view of the subcultures as not just rebellious and resistant by instead emphasizing their artistic and performative skills. Moreover, mediatization has set off a process of mass incorporation of skaters and graffiti writers through mediation and remediation of their style and symbolic capital. The main signifiers of in-group cohesiveness and dissociation from society have not only been neutralized and naturalized but also niched to young consumers as oppositional and therefore fashionable. Nevertheless, skaters and graffiti writers produce their nearly professional videos and photos and share them on the internet in hopes of gaining not only recognition but also access to job opportunities and commercial projects.

Overall, it seems that crimes of style have surfaced in mainstream culture, thus losing their 'criminal' or 'delinquent' character. Yet it remains possible that the underground and deviant subcultural members prefer to remain detached from mainstream culture while still being influenced by mediatization. For example, Banksy, an infamous street and graffiti 
artist who carefully guards his anonymity, recently directed and appeared in an Oscar-nominated movie about underground street art (Exit Through the Gift Shop, 2010). Although Banksy was blacked out in order to keep himself unrecognizable, this documentary is an indication that the underground - the world of street art and graffiti - has opened itself up to media exposure - and branding.

This last aspect is interesting for future mediatization research as we are obviously only just now beginning to understand the relationships between mediatization and commercialization or commodification. How, precisely, do these (meta-)processes relate and interact, and what are their consequences? Here, we have seen that mediatization and the intentional mediation of subcultural practices can have the aim of going commercial and commodifying practices, but the unintended consequences of this are less clear.

Another possibility for further analysis could be to focus not only on skating and graffiti writing subcultures but to also examine other subcultures, such as those organized around music and $B M X$ riding, and to undertake comparative research among them. This can deepen our understanding of possible differences in their media(-related) practices and the extent to which these can be explained by the (sub)cultures to which these relate.

Finally, due to its explorative character and ethnographic approach, which involved rather intensive data collection, the number of respondents in this research has been relatively limited. An interesting follow-up study could therefore be to focus on one specific subculture and analyze its internal dynamics, possible role differentiation regarding media(related) practices, and related hierarchies or organizational structures. These can also differ depending on the regional context under study: As our American respondent pointed out, for instance, skateboarding and graffiti are approached much more restrictively by authorities in America. This implies that research on the mediatization of subcultures should ideally focus not only on people's media-related practices but also pay close attention to relevant contextual, structural, policy, and legal contexts.

\section{Notes}

1. These are (a) art, performance, spectacle; (b) in-group cohesiveness; (c) mass incorporation; (d) (life) style; (e) commercialization; and (f) identity formation.

2. A tag is a graffiti writer's name or pseudonym. A throw-up is graffiti slang for a quick and easy-to-paint monochrome outline.

3. Trickipedia is the general education website for skateboarding tricks, founded by the Berrics (see http:// theberrics.com/trickipedia.php). 


\section{Acknowledgment}

The authors would like to thank the reviewers for their useful comments and Simon Orpana for his helpful feedback on an earlier version of this article.

\section{References}

Anderson, C. (2002). The effects of media violence on society. Science, 295, 2377-2379.

Asp, K. (1990). Medialization, Media logic and Mediarchy, The Nordicom Review of Nordic Mass Communication Research, 2, 47-50.

Atkinson, M., \& Young, K. (Eds.). (2008). Tribal play: subcultural journeys through sport. Bingley: Emerald Group Publishing.

Campus, D. (2010). Mediatization and personalization of politics in Italy and France: The cases of Berlusconi and Sarkozy. The International Journal of Press/Politics, 15(2), 219-235.

Couldry, N. (2004). Theorising media as practice. Social Semiotics, 14(2), 115-132.

Couldry, N. (2008). Mediatization or mediation? Alternative understanding of the emergent space of digital storytelling. New Media \& Society, 10(3), 373-391.

Couldry, N. (2012). Media, Society, World: Social Theory and Digital Media Practice. Cambridge: Polity.

Dayan, D., \& Katz, E. (1992). Media events: the live broadcasting of history. Cambridge: Harvard University Press.

Dickens, L. (2008). Placing post-graffiti: the journey of the Peckham Rock. Cultural Geographies, 15, 471-496. Donnelly, M.K. (2008). Alternative and mainstream: revisiting the sociological analysis of skateboarding. In M. Atkinson, \& K. Young (Eds.), Tribal play: subcultural journeys through sport (pp. 197-214). Bingley: Emerald Group Publishing.

Driessens, O., Raeymaeckers, K., Verstraeten, H., \& Vandenbussche, S. (2010). Personalization according to politicians: A practice theoretical analysis of mediatization, Communications, 35(3), 309-26.

Duda, K. (2010). Graffiti writing as a form of subcultural practice. Diskrepancija, 10(14/15), 72-82.

Ferrell, J. (1996). Crimes of style: Urban graffiti and the politics of criminality. Boston: Northeastern University Press.

Ferrell, J. (1999). Cultural criminology. Annual Review of Sociology, 25, 395-418.

Ferrell, J., Milovanovic, D., \& Lyng, S. (2001). Edgework, media practices, and the elongation of meaning. Theoretical Criminology, 5(2), 177-202.

Ferrell, J., \& Sanders, C. (1995). Cultural criminology. Boston: Northeastern University Press.

Furness, Z. (2005).“Put the fun between your legs!”: The politics and counterculture of bicycle. Unpublished dissertation: University of Pittsburgh.

Greer, C. (2009). Crime and media: A reader. London: Routledge.

Hall, S., \& Jefferson, T. (Eds.). (1993). Resistance through rituals: Youth subcultures in post-war Britain. London: Routledge.

Hamm, M.S., \& Ferrell, J. (1994). Rap, cops, and crime: Clarifying the „cop killer" controversy. ACJS Today, 13(1), 29.

Hartmann, M. (2009). Everyday: Domestication of mediatization or mediatized domestication? In K. Lundby (Ed.), Mediatization: Concept, changes, consequences (pp. 225-242). New York: Peter Lang.

Hayward, K.J., \& Young, J. (2004). Cultural criminology: some notes on the script. Theoretical Criminology, $8(3), 259-273$.

Hebdige, D. (1979). Subculture: The Meaning of Style. New York: Methuen. 
Hepp, A. (2009). Differentiation: Mediatization and cultural change. In K. Lundby (Ed.), Mediatization: Concept, changes, consequences (pp. 139-158). New York: Peter Lang.

Hepp, A. (2012). Mediatization and the 'molding force'of the media. Communications, 37(1), 1-28.

Hepp, A., Hjarvard, S., \& Lundby, K. (2010). Mediatization - empirical perspectives: An introduction to a special issue. Communications, 35(3), 223-228.

Hjarvard, S. (2004). From bricks to bytes: The Mediatization of a Global Toy Industry. In I. Bondebjerg, \& P. Golding (Eds.), European Culture and the Media (pp. 43-63). Bristol: Intellect.

Hjarvard, S. (2008a). The mediatization of religion: A theory of the mass media as agents of religious change. Northern Lights: Film \& Media Studies Yearbook, 6(1), 9-26.

Hjarvard, S. (2008b). The mediatization of society: A theory of media as agents of social and cultural change. Nordicom Review, 29(2), 105-134.

Hoover, S.M. (2009). Complexities: The case of religious cultures. In K. Lundby (Ed.), Mediatization: Concept, changes, consequences (pp. 123-138). New York: Peter Lang.

Hughes, M.L. (2009). Street art \& graffiti art: developing an understanding. Art \& Design Theses. Retrieved April 1, 2011, from http://digitalarchive.gsu.edu/art_design_theses/50.

Jansson, A. (2002). The Mediatization of Consumption. Journal of Consumer Culture, 2(1), 5-31.

Jewkes, Y. (2004). Media and Crime: Key approaches to criminology. Thousand Oaks: Sage.

Kepplinger, H. M. (2002). Mediatization of politics: Theory and data. Journal of Communication, 52(4), 972986.

Kidd-Hewitt, D., \& Osborne, R. (1995). Crime and the media: the post-modern spectacle. Michigan: Pluto Press.

Kolenic, A.J. (2009). Madness in the Making: Creating and Denying Narratives from Virginia Tech to Gotham City. The Journal of Popular Culture, 42(6), 1023-1039.

Krotz, F. (2001). The mediatization of communicative action: The change in everyday and social relations, culture and society through media. Wiesbaden: Westdeutscher Verlag.

Livingstone, S. (2009). On the Mediation of Everything: ICA Presidential Address 2008. Journal of Communication, 59(1), 1-18.

Lundby, K. (2009a). Introduction: 'Mediatization' as key. In K. Lundby (Ed.), Mediatization: concept, changes, consequences (pp. 1-18). New York: Peter Lang.

Lundby, K. (2009b). Media logic: looking for social interaction. In K. Lundby (Ed.), Mediatization: concept, changes, consequences (pp. 101-119). New York: Peter Lang.

MacDonald, N. (2001). The graffiti subculture: Youth, masculinity, and identity in London and New York. New York: Palgrave Macmillan.

Manco, T. (2002). Stencil Graffiti. New York: Thames \& Hudson.

Marchart, O. (2003). Bridging the micro-macro gap: Is there such a thing as post-subcultural politics? In D. Muggleton, \& R. Weinzierl (Eds.), The post-subcultures reader (pp. 83-101). Oxford: Berg.

McRobbie, A., \& Thornton, S. (1995). 'Moral Panic' for multi-mediated social worlds. The British Journal of Sociology, 46(4), 559-574.

Muggleton, D., \& Weinzierl, R. (Eds.) (2003). The post-subcultures reader. Oxford: Berg.

Nelson, W. (2010). The historical mediatization of BMX-freestyle cycling. Sport in Society: Cultures, Commerce, Media, Politics, 13(7), 1152-1169.

Orpana, S. (2011). Public domain: An apocalypse of social space in streetstyle skateboarding culture. Psychogeographies, 1(1), Retrieved January 5, 2013, from http://www.psychogeographies.ca/Public_Domain_ files/Orpana_Final.pdf.

Pietrosanti, S. (2010). Behind the tag: A journey with the graffiti writers of European walls. Unpublished manuscript: University of Amsterdam. 
Reckwitz, A. (2002). Toward a theory of social practices: A development in culturalist theorizing, European Journal of Social Theory, 5(2), 243-263.

Schatzki, T.R. (1996). Social practices: A Wittgensteinian approach to human activity and the social. Cambridge: Cambridge University Press.

Skjulstad, S. (2009). Dressing up: The mediatization of fashion online. In K. Lundby (Ed.), Mediatization: Concept, changes, consequences (pp. 179-202). New York: Peter Lang.

Rinehart, R. (2008). ESPN's X games: Contests of opposition, resistance and conformity, and negotiation. In M. Atkinson, \& K. Young (Eds.), Tribal play: subcultural journeys through sport (pp. 175-195). UK: Emerald.

Schrott, A. (2009). Dimensions: Catch-all label or technical term. In K. Lundby (Ed.). Mediatization: Concept, changes, consequences (pp. 41-61). New York: Peter Lang.

Silverstone, R. (2007). Media and morality: On the rise of the mediapolis. Cambridge: Polity.

Snyder, G.J. (2012). The city and the subculture career: Professional street skateboarding in LA. Ethnography, 13(3), 306-329.

Steffensmeier, D. (1996). Gender and crime: Toward a gendered theory of female offending. Annual Review of Sociology, 22, 459-58.

Thornton, S. (1995). Club cultures: Music, media and subcultural capital. Cambridge: Polity.

Weingart, P. (1998). Science and the media. Research Policy, 27(8), 869-879.

Willard, M.N. (1998). Seance, tricknowledgy, skateboarding, and the space of youth. In J. Austin, \& M.N. Willard (Eds.), Generations of Youth (pp. 327-346). New York: New York University Press.

Yochim, E. (2007). "This is how I think": Skate life, corresponding cultures and alternative white masculinities. Unpublished manuscript: University of Michigan.

Kameliya Encheva

MA

Department of Communication Sciences,

Ghent University, Belgium

Kameliya.Encheva@gmail.com

Olivier Driessens

PhD Candidate

Department of Communication Sciences

Ghent University, Belgium

Olivier.Driessens@UGent.be

Hans Verstraeten

Professor, PhD

Department of Communication Sciences

Ghent University, Belgium

Hans.Verstraeten@UGent.be 